\title{
Comentarios
}

\section{En la ruta de las elecciones \\ del 12 de marzo}

Los dos primeros meses del año 2000 han estado marcados por la campaña electoral con vistas a las elecciones legislativas y municipales del 12 de marzo. Las notas características de la coyuntura han sido, como en anteriores ocasiones, la saturación publicitaria, las acusaciones y contraacusaciones entre los partidos y sus candidatos y las violaciones abiertas a la legislación electoral'. Todo ello en un clima de descontento social generalizado, de creciente desconfianza hacia la política y los políticos, de incertidumbre acerca del futuro del país y de proliferación de actitudes y comportamientos autoritarios, emanados de las altas esferas del Estado. De aquí que una de las novedades de la actual coyuntura electoral no radique tanto en lo que los partidos y sus candidatos ofrecen, sino más bien en lo crítico de la situación socio-económica, que servirá de escenario a la contienda electoral del 12 de marzo. Ciertamente, desde la firma de los acuerdos de paz, nunca como ahora, el país se había visto inmerso un clima de malestar social tan generalizado, con una clase política cuyo descrédito está llegando al límite, una conducción gubernamental más que cuestionable y la ausencia de propuestas realistas de solución a la actual crisis nacional. Este es escenario de las elecciones del 12 de marzo. Aquí es donde los partidos y sus candidatos se batirán en duelo, para determinar quiénes de ellos decidirán, para bien o para mal, cómo salir del atolladero en el que se encuentra el país en materia social y económica.
Dicho lo anterior, es preciso hacer notar que, como ya es tradición y al margen de cualquier consideración legal, el proselitismo partidario comenzó prácticamente desde mediados del año pasado, cuando algunos de los partidos dieron a conocer a sus posibles candidatos a alcalde, en los distintos municipios del país. Los procesos de selección de esos candidatos y los eventos montados para tal fin se convirtieron en parte de las estrategias diseñadas para atraer adeptos a los respectivos partidos. Al cierre del año, algunas figuras políticas, como Luis Cardenal, candidato de ARENA para la alcaldía de San Salvador, visitaron colonias populares y mercados con el claro propósito de promover su imagen y la de su partido. Todo esto, al parecer, como parte de una estrategia de largo plazo, diseñada por los asesores de ARENA, desde las elecciones presidenciales de marzo de 1999, y encaminada a revertir unas tendencias electorales que se perfilaban como contrarias para los intereses del partido de derecha. Al parecer, desde aquel entonces, los asesores de ARENA cayeron en la cuenta de que si este partido quería asegurarse el control del gobierno por unos cuantos periodos más ya no bastaba con asegurar el mínimo para ganar y que, en consecuencia, debía comenzar cuanto antes para revertir no tanto el crecimiento de su más cercano contendiente - el FMLN-, sino el propio estancamiento o incluso decrecimiento electoral.

1. A ello se suma el asesinato de cuatro militantes del Partido de Acción Nacional, según voceros de ese partido, por motivos políticos y cuya responsabilidad apunta, al menos en dos casos, a miembros del partido ARENA. Voceros de este partido -incluido el presidente Francisco Flores - han negado la naturaleza política de los asesinatos de los miembros del PAN. 
Así, pues, la coyuntura electoral se abrió en El Salvador desde el año pasado, lo cual hizo que el quehacer de los partidos, hacia dentro, estuviera marcado por los arreglos y las disputas acerca de quiénes iban a figurar como candidatos a alcaldes y diputados; mientras que, hacia fuera, se caracterizó por el esfuerzo, tanto de los partidos como de sus miembros, de hacer sentir su presencia en la sociedad. Obviamente, se trató de dos dinámicas distintas, pero relacionadas entre sí.

El quehacer interno de partidos supuso, de nueva cuenta, que las rivalidades políticas -muchas de ellas teñidas de ambiciones personales y afán de protagonismo- se convirtieran en uno de los ejes principales de su vida interna. Fue en el Partido Demócrata Cristiano (PDC) en donde ello fue más notorio, pues en su interior volvieron a plantearse las disputas que han acompañado a Ronal Umaña, desde que este se convirtió en una figura clave de la cúpula pedecista. Umaña fue relevado del mando del partido, pero para llegar a eso, las fracturas fueron inevitables y sus propósitos de retornar a la cúpula pedecista constituyen, aun ahora, una amenaza para la frágil estabilidad partidaria. Pero también en los partidos que pretenden aglutinarse en el siempre problemático "centro político", las disputas intestinas estuvieron a la orden del día, ya fuera por el tema de la bandera única o ya fuera por los intentos de cualquiera de los aliados -o de sus líderes- de convertirse en el principal portavoz del confuso proyecto centrista. Este apartado, de nuevo, deja sobre la mesa de discusión la (ya vieja) pregunta acerca de la viabilidad del centro político. Y es que por más que sus portavoces insistan en su fortaleza y perspectivas, no hay nada en la realidad que sustente su optimismo: la volatilidad y los compromisos efímeros entre sus miembros, además de la ausencia de un proyecto político coherente y viable, son sus características más sobresalientes.

De lo anterior no se sigue, empero, que no sea saludable para la democratización del país la conformación de un bloque de partidos minoritarios - llámense de centro o no- comprometidos con la búsqueda de soluciones para los problemas nacionales. Pero los partidos minoritarios actualmente existentes - y sus liderazgos - han fallado desde todo punto de vista en esta tarea. De llevar a miembros suyos a la Asamblea Legislativa, ipodrán fuerzas políticas como la de la Unión Social Cristiana (USC), con el respaldo de la Iniciativa Ciudadana, o el Partido de Acción Nacional (PAN), revertir los dinamismos que han caracterizado hasta ahora el quehacer de los diputados de los partidos pequeños? Nadie lo sabe con exactitud pues, aunque voceros de esas organizaciones sostienen su compromiso insobornable con la promoción del bien común, la lucha por el respeto de los derechos de los sectores mayoritarios de la población y el combate contra la corrupción, nadie puede asegurar que, una vez en la Asamblea Legislativa -de acceder a algunos escaños-, van a estar dispuestos a cumplir sus promesas. Peor aún, nadie puede asegurar que, aunque lo quieran, vayan a poder oponer una resistencia eficaz a la lógica que ha prevalecido hasta ahora en el parlamento. Sin embargo, si lograran hacerlo - siendo imprescindible para ello que obtengan un número significativo de escaños (para lo cual, antes, tienen que convencer al electorado de los beneficios de sus propuestas)-, entonces, una nueva correlación de fuerzas se podría imponer en la Asamblea Legislativa. En ella, muy probablemente, el FMLN encontraría un espacio más favorable que ARENA para llevar adelante una serie de iniciativas que beneficien a los sectores populares. Por el momento, se puede sospechar que las propuestas emanadas desde el PAN y la USC no han calado suficientemente en el imaginario colectivo como para traducirse en un número significativo de votos. Quién sabe si lo logren de aquí al 12 de marzo, aunque en un ambiente tan caldeado como en el actual pueden ocurrir sorpresas inesperadas.

Mientras tanto, los dos partidos mayoritarios -ARENA y el FMLN - han sabido mantener, hasta ahora, un buen ritmo electoral. Para comenzar, las rivalidades fueron acalladas por la fuerza de la disciplina interna, acerca de la cual ambas instituciones partidarias saben lo suficiente: los antecedentes de escuadrón de la muerte de la primera y de ejército de la segunda, aun en tiempos de postguerra, tienen un peso indudable a la hora de regular el comportamiento de los militantes. De este modo, una vez suscitada la coyuntura electoral, ni ARENA ni el FMLN vieron en riesgo sus respectivos proyectos partidarios, por más que al interior de ellos se libraran importantes batallas entre sus viejas guardias (y sus allegados) y los abanderados (presuntos o reales) de la renovación partidaria. En otras palabras, en ARENA, los paquistas terminaron conviviendo con la vieja guardia arenera -a cuya cabeza se encuentra Alfredo Cristiani-, mientras que, en el FMLN, los facundistas terminaron por hacer las pases con los ortodoxos. Lograda una tregua interna, ambos partidos han podido de- 
dicar sus energías y talentos para el diseño e implementación de la estrategia que, según los cálculos de sus mentes más lúcidas, le van a permitir sumar mayor cantidad de votos a sus candidatos. Con ello, han sacado ventaja al resto de partidos, la mayoría de los cuales ni ha superado sus conflictos internos ni parecen tener claro a qué atenerse en los comicios del próximo 12 de marzo. Por mero análisis político, en la carrera electoral $-\mathrm{y}$ al margen de las simpatías o antipatías que cada una de ellos pueda suscitar-, ARENA y el FMLN llevan desde ya la delantera respecto de los demás partidos, con lo cual se van colocando como las dos fuerzas políticas que van a acumular el mayor caudal de votos. $\mathrm{Ni}$ qué decir liene que con lo anterior no se apunta nada nuevo; sólo se confirma una tendencia política que se ha fraguado desde la firma de la paz y se señalan algunos elementos que, en la actual coyuntura electoral, han desbrozado el camino para que tanto ARENA como el FMLN mantengan su predominio político.

Sobre lo segundo - la presencia social de los partidos y sus figuras-, es claro que una de las lecciones básicas de la práctica política es que uno de los requisitos mínimos para conseguir votos es fijar en el imaginario colectivo rostros y emblemas que los conviertan en referentes cotidianos para los ciudadanos. Ahora bien, esta lección puede traducirse en una saturación publicitaria - spots televisivos y radiofónicos, pinta y pega de propagada, visitas a la población- justo desde que ley electoral declara abierta la campaña hasta que la misma se cierra. Según sus recursos, habilidades y creatividad esto lo hacen todos los partidos hasta la saciedad. El objetivo es convencer a los ciudadanos, en un corto periodo de tiempo, de que la oferta política propia es la mejor, la que va a resolver de un tajo todos los problemas que aquejan a la población. Esto tiene sus costos: para el electorado, la saturación; para los partidos y sus candidatos, la indistinción de ofertas. Por lo primero, los ciudadanos terminan por sentirse asqueados de la propaganda política; por lo segundo, a cada partido le cuesta distanciarse de lo que otros ofrecen, puesto que al ofrecer cada uno de ellos una solución para todo - desde el tema del medio ambiente hasta el de la violencia familiar- terminan por decir y ofrecer lo mismo, sin que quepa hacerse una idea

de qué es aquello que los distingue y los puede hacer preferibles a la hora de la votación.

Sin embargo, no todos los partidos concentran la totalidad de sus esfuerzos publicitarios exclusivamente en el periodo estipulado por la ley. ARENA el que menos pues, como una maquinaria hecha para ganar elecciones que es, no le apuesta sólo a lo que se puede hacer durante la campaña formalmente establecida, sino que también -y quizás más - le apuesta a lo que se pueda hacer mucho antes de la misma. Y, como bien saben los asesores de ARENA, bastante de lo que se puede hacer consiste en lograr que sus candidatos, por muy desconocidos que sean para los sectores populares - véase si no es este el caso de Francisco Flores y Luis Cardenal-, sean personajes socialmente familiares, conocidos por lodos, cercanos al habitante del cantón más recóndito del país. La idea es que después de un cierto tiempo - tras la puesta en marcha del marketing adecuado- todos hablen de "Paquito" como si fuera uno de los conocidos de la familia o que todos hablen de Lourdes sin tener necesidad de decir que se trata de la primera dama, la esposa del presidente Francisco Flores -que para los conocidos es "Paquito"-. Con Luis Cardenal y su esposa, Regina, sucede un fenómeno publicitario similar al sucedido con Flores. Sólo que con Luis Cardenal, por aquello de que su rival es Héctor Silva - a quien mucho reconocen solamente como "Silva"-, no se usa el diminutivo de Luisito, sino nada más "Cardenal". Pero Cardenal se está haciendo familiar para todos: visita los mercados, bebe refresco, saluda a la gente del pueblo. Es decir, todos lo conocen, es alguien cercano a cualquier ciudadano. Y no se diga más de Regi- 
na: aunque acompaña a su esposo, ella liene su propio nombre y su propio espacio de reconocimiento: es premiada por doquier y reconocida por sus méritos en pro de las causas más nobles. Aquí, como en otras cosas - por ejemplo, en recursos económicos y en disciplina interna-, ARENA está por delante de los demás partidos. ¿Pueden el resto de partidos ponerse a la par de ARENA y disputarle la supremacía de la que hasta ahora ha gozado? En recursos económicos, difícil. En disciplina interna, quizá sólo el FMLN pueda ponérsele a la par.

Así, visto hacia adentro, ARENA tiene mayores fortalezas que el resto de partidos políticos, exceptuando al FMLN, en áreas clave como la disciplina partidaria y la capacidad para movilizar a la militancia. Hacia fuera, la presencia social de ARENA y a sus candidatos es trabajada con mucha antelación respecto del inicio formal de la campaña electoral. Esto permite al partido y sus candidatos calar en el imaginario colectivo, lo cual es básico para orientar una preferencia electoral: pocos querrán dar su voto a un candidato que no conocen o conocen poco. Entonces, ¿es imbatible ARENA?

Hasta ahora, sus fortalezas internas y su habilidad para promocionar socialmente a sus candidatos le han dado buenos resultados. Sin embargo, ello no puede ser eterno, al menos por dos razones: la primera, porque gobernar desgasta, sobre todo si las políticas económicas y sociales laceran los intereses de los sectores populares. A ARENA, como partido de gobiemo, se le achacan, desde diversos sectores sociales, graves desaciertos en materia social y económica. Y cuando esos desaciertos, lejos de ser corregidos, han sido repetidos una y otra vez, no pueden ser borrados ni por la más ingeniosa estrategia de marketing político. En segundo lugar, los partidos políticos -especialmente el FMLN - no van a estar todo el tiempo a la zaga de ARENA, en cuanto al conocimiento de técnicas y estrategias de publicidad electoral. Una vez que el FMLN -o cualquier otro partido que emerja con fucrza- asuma en serio el componente de mercado de la política, el partido ARENA se las verá en dificultades. Los asesores del partido lo saben: no hay otro modo de explicar la agresividad de su actual campaña electoral, especialmente en lo que se refiere a los esfuerzos para impedir la reelección de Héctor Silva al frente de la alcaldía de San Salvador.

Así las cosas, es presumible que en las elecciones del 12 de marzo, ARENA saque ventaja de las inercias que hasta ahora le han permitido mantenerse en el poder, aunque posiblemente no donde más quisiera: en la alcaldía de San Salvador, cuya reconquista se ha convertido en uno de los ejes fundamentales de su campaña política. Quizás han caído en la cuenta los estrategas del partido de que Héctor Silva, de ser releecto como alcalde, se convertiría en una figura presidenciable de primera importancia. De aquí que, para ARENA, la recuperación de la alcaldía de San Salvador no sea un fin en sí mismo, sino un medio para cuidarse de un posible revés político en las siguientes elecciones presidenciales. De allí los denodados esfuerzos de ARENA — apoyado abiertamente por El Diario de Hoy - por encontrar (o fabricar) pruebas que descalifiquen públicamente la gestión edilicia de Silva.

La lectura del FMLN parece ser la misma de ARENA, sólo que en sentido inverso: una victoria de Silva apuntalaría al Frente en vistas a sus aspiraciones de acceder al ejecutivo, en un futuro no muy lejano. El Frente le ha tomado la palabra a ARENA y ha asumido como una de sus principales metas la defensa de la alcaldía de San Salvador, forzando al partido de derecha a usar una enorme cantidad de recursos para promover a un candidato que tiene todas las de perder. De ese modo, la contienda Silva-Cardenal ha hecho pasar a un segundo plano lo más importante de unas elecciones municipales y legislativas, al menos desde la perspectiva del proceso de democratización del país: la posibilidad de reestructurar los ejes de poder prevalecientes en la Asamblea Legislativa y la posibilidad de fortalecer o reencauzar el trabajo de los gobiernos locales.

Luis Armando González 